\title{
A STUDY OF ELECTROCARDIOGRAPHIC, ECHOCARDIOGRAPHIC AND HAEMATOLOGICAL FINDINGS IN CHRONIC OBSTRUCTIVE LUNG DISEASE
}

\author{
D. Seshagirirao ${ }^{1}$, M. Thriveni $^{2}$ \\ ${ }_{1}^{1}$ Professor, Department of Pulmonary Medicine, Guntur Medical College. \\ 2 Postgraduate Student, Department of Pulmonary Medicine, Guntur Medical College.
}

\begin{abstract}
\section{BACKGROUND}

Chronic Obstructive Pulmonary Disease (COPD) has been defined as a disease state characterised by airflow limitation that is not fully reversible. ${ }^{1}$ The GOLD guidelines define COPD as- "A preventable and treatable disease with some significant extrapulmonary effects that may contribute to the severity in the individual patient. Its pulmonary component is characterised by airflow limitation that is not fully reversible. The airflow limitation is usually progressive and associated with an abnormal inflammatory response of the lung to noxious particles or gases." 2 COPD is the fourth leading cause of death and affects > 16 million persons in the United States. COPD is also a disease of increasing public health importance around the world. GOLD estimates suggest that COPD will rise from the sixth to the third most common cause of death worldwide by 2020. In India, COPD is the $2^{\text {nd }}$ most common lung disorder after pulmonary tuberculosis. ${ }^{3}$ The disease is frequently encountered in the middle-aged patients and is rare below the age of 35 . It affects males more than females. It is equally prevalent in rural and urban areas. ${ }^{3}$
\end{abstract}

\section{MATERIALS AND METHODS}

The present study was a cross-sectional descriptive study, conducted in Department of Pulmonary Medicine in ID Hospital, Guntur. 100 COPD patients who were attending OP were included in the study. The study period was January 2015 to June 2016 . The data was analysed using SPSS (Statistical Package for Social Sciences) version 20. Results were expressed in terms percentage, means, proportions and standard deviation and Chi-square test were applied and $\mathrm{p}<0.05$ was considered as statistically significant.

\section{RESULTS}

The present study included 100 patients with stable chronic obstructive pulmonary disease attending Department of Pulmonary Medicine, GGH, Guntur. After satisfying the inclusion and exclusion criteria, the haematological findings, ECG findings and Echocardiac findings are studied and compared with other studies.

\section{CONCLUSION}

- $\quad$ The lung function parameters namely $\mathrm{FEV}_{1} \%$ has significant inverse relation between the severity of COPD, progressively decreasing with the increasing severity.

- On electrocardiography, the most common abnormality observed was ' $\mathrm{P}$ ' pulmonale, but $\mathrm{R} / \mathrm{S}$ ratio in $\mathrm{V}_{6}<1$ associated significantly with the severity of COPD.

- In the Echocardiographic study, the right heart parameters were significantly increased in Mild, Moderate and Severe and Very Severe COPD respectively.

- Our study emphasises the importance of haematological parameters namely $\mathrm{Hb} \%$ and PCV, were significantly increased in Mild, Moderate and Severe and Very Severe Chronic Obstructive Pulmonary Diseases respectively.

\section{KEYWORDS}

COPD, ECG, Echocardiography, Haematological Values.

HOW TO CITE THIS ARTICLE: Seshagirirao D, Thriveni M. A study of electrocardiographic, echocardiographic and haematological findings in chronic obstructive lung disease. J. Evolution Med. Dent. Sci. 2017;6(42):3297-3304, D0I: $10.14260 /$ Jemds/2017/714

\section{BACKGROUND}

A cross-sectional descriptive study was conducted among 100 COPD patients attending OP in the Department of Pulmonary Medicine in ID Hospital Guntur, after satisfying inclusion and exclusion criteria. COPD patients are grouped by value of FEV1 divided into 4 groups- mild, moderate, severe and very severe by spirometry.

Financial or Other, Competing Interest: None.

Submission 12-04-2017, Peer Review 13-05-2017,

Acceptance 19-05-2017, Published 25-05-2017.

Corresponding Author:

Dr. D. Seshagirirao,

\#1-9-23, Sriramnagar,

Kakinada-533003.

E-mail: drdsraosai@gmail.com

DOI: $10.14260 /$ jemds $/ 2017 / 714$
Haematological study of haemoglobin percentage and PCV values are measured in 4 groups. ECG changes are studied in 4 groups; echocardiographic values are also included. These are compared in 4 groups of COPD patients.

\section{Aims}

1. To study the ECG and ECHO and Haematological changes in COPD patients.

2. To study these findings in association with duration and severity of the disease.

3. To compare the results of haematological, electrocardiographic and echocardiographic examination findings in detecting right ventricular dysfunction in COPD. 


\section{Inclusion Criteria}

- $\quad$ Adult male and female patients aged more than 35 years with a history suggestive of chronic obstructive pulmonary airway disease were selected attending Department of Pulmonary Medicine, GGH, Guntur.

- The diagnosis of chronic obstructive pulmonary diseases made by symptoms in the history and confirmed by physical examination, radiographic examination and lung spirometry for airway obstruction by spiroanalyser.

- The patients who are diagnosed as having chronic obstructive pulmonary disease as per GOLD guidelines with FEV1/FVC $<70 \%$ are further divided into 4 groups.

- Group I- Patients are to be selected who fulfil the above criteria and graded as mild group COPD based on predicted FEV1 (> 80\%) of predicted value of stage 1 .

- $\quad$ Group II- Patients are to be selected who fulfil the above criteria and graded as moderate COPD based on predicted FEV1 (50\% - 80\% of pred value) of stage 2 .

- $\quad$ Group III- Patients are to be selected who fulfil the above criteria and graded as severe COPD based on predicted FEV1 (30\% - $50 \%$ of pred value) of stage 3 .

- Group IV- Patients are to be selected who fulfil the above criteria and graded as very severe COPD based on predicted FEV1 $(<30 \%$ of pred value) of stage 4 .

\section{Exclusion Criteria}

1. Cases to be excluded from the present study are primary diagnosis of bronchial asthma, known sleep apnoea, lung cancer, known left ventricular dysfunction. Other debilitating cancers, poorly controlled hypertension, significant valvular disease and known coronary artery diseases (Angina, Ischaemic changes in resting ECG or documented history of myocardial infarction).

2. Very poor echogenic subjects in whom, meaningful echocardiographic examination could not be performed were also excluded from the present study.

3. Patients with active pulmonary Koch's.

\section{MATERIALS AND METHODS}

\section{Source of the Data}

The present study was conducted in Department of Pulmonary Medicine in ID Hospital, Guntur. 100 COPD patients who were attending OP were included in the study. The study period was January 2015 to June 2016.

\section{Design}

Cross-Sectional descriptive study.

\section{Procedure}

After recruitment for the study and doing routine investigations with special reference to $\mathrm{Hb} \%$ and PCV (as per Proforma), the patients were subjected to the following examination-

1. Physical Examination- Thorough physical examination was done to determine any direct or indirect evidence of cor pulmonale.

2. Radiographic Examination- Chest x-ray postero-anterior view was obtained to detect right heart enlargement and/or pulmonary artery dilatation.

3. Electrocardiographic assessment- A standard 12-lead electrocardiography was obtained for each using a portable ECG machine. The following criteria was used to detect right ventricular hypertrophy.
a. P pulmonale pattern ( $\mathrm{P}$ wave $>2.5 \mathrm{~mm}$ ) in leads II, III, avF.
b. Right axis deviation of QRS complex.
c. $\mathrm{R} / \mathrm{S}$ amplitude ratio in V6 is less than 1 .
d. R/S amplitude ratio in V1 is more than 1 .
e. Clockwise rotation of the electrical axis.
f. Right bundle branch block.
g. S1, Q3 or S1, S2, S3 patterns.

\section{Spirometry}

The spirometry was carried out with help of BPL ARPEMIS spiroanalyser with flow volume loop and volume time curve. The test was conducted as per the latest standards developed by ATS and ERS.

\section{Procedures to Determine the Lung Volumes}

The subject was instructed to take a deep inspiration, then close the lips round the mouth piece (as not to leak the inspired air) and blow out as hard and fast as possible. Care was taken to see that inspiration was full and unhurried and expiration should be continuous without a pause and hesitation.

It is the volume of air that can be forcibly exhaled (as fast as possible) after a maximal inspiration. It is expressed in litres.

(Normal value is 4000 to $5000 \mathrm{~mL}$ ).

\section{Forced Expiratory Volume Timed (FEVT)}

It is the fraction of the vital capacity expired at the end of first, second or third seconds of expiration. In this case, FEV1 is defined as the volume of air expelled in first second from the start of maximum expiratory effort of the forced vital capacity. It is expressed in litres. Forced expiratory volume timed (in Sec) as a percentage of forced vital capacity (FEV1\%). It is the percentage of the forced vital capacity, which is expelled in the first one second of maximum expiratory effort.

\section{Echocardiographic Examination}

All the individuals of the 3 groups are subjected to echocardiographic examination. During the echocardiographic studies, recommendations of the American Society of Echocardiography regarding nomenclature, standards and quantification in M-mode and 2-D echo are followed. The following echocardiographic parameters are to be studied.

\section{M-Mode Echocardiography}

The recordings were made in parasternal view. The subjects were positioned in supine or 15-45 left lateral position to minimise distortion of the right-sided chambers, since these chambers were of particular interest in this study. All the measurements in the M-mode were taken from "Leading Edge" to "Leading Edge" as proposed by American Society of Echocardiography.

With direct 2-D guidance using a moving cursor, the following measurements were recorded in M-mode.

Right ventricular free wall thickness (Anterior wall):- It was measured only on echocardiogram, in which the epicardial and endocardial surfaces had been brought out by damping and if required by a high frequency transducer. The thickness was measured as the distance between the 
epicardial surface echo and the endocardial surface echo. A recording of equal to or more than $0.6 \mathrm{~cm}$ was taken as evidence of right ventricular hypertrophy, in subcostal and four-chamber view.

\section{B-Mode Two-Dimensional Echocardiography}

While performing this study, the subject was positioned in the supine position. A four-chamber view was obtained by keeping the transducer at the point of maximal impulse and angling the pointer of the transducer at $90^{\circ}$ to the right shoulder. The adjustments were made carefully until an image of all four chambers with maximal length of right and left ventricle and mitral and tricuspid valve visualisation was obtained.

The adjustments were made to the point, at which the endocardium was visualised without excessive loss of lateral or axial resolution. Still frames of right ventricle at end diastole and right atrium at end systole were projected on the monitor screen and measurements of each chamber at its largest size was taken.
The following dimensions were measured.

1. Right ventricular area (End-Diastole)- This was obtained by tracing the end diastolic image on the screen and taking measurements directly from the ultrasound computer.

2. Right atrial area (End-systole)- This was measured in a similar manner to that of right ventricular area, but in end-systole.

\section{RESULTS}

The present study included 100 patients with stable chronic obstructive pulmonary disease attending Department of Pulmonary Medicine, GGH, Guntur.

\section{Age Distribution in COPD Patients}

The age of the patients being studied ranged between $40 \mathrm{yrs}$. to 81 yrs. The mild COPD group ranged from 41 yrs. to $77 \mathrm{yrs}$. The moderate COPD group ranged from 42 yrs. to 78 yrs. The ages in severe COPD group were 40 yrs. to $78 \mathrm{yrs}$. and in very severe COPD group was 62 yrs. to 82 yrs.

\begin{tabular}{|c|c|c|c|c|c|c|c|c|c|c|}
\hline \multirow[t]{2}{*}{ Age (In Years) } & \multicolumn{2}{|c|}{$\begin{array}{l}\text { Mild COPD } \\
(\mathrm{n}=5)\end{array}$} & \multicolumn{2}{|c|}{$\begin{array}{c}\text { Moderate COPD } \\
(n=79)\end{array}$} & \multicolumn{2}{|c|}{$\begin{array}{c}\text { Severe COPD } \\
(n=13)\end{array}$} & \multicolumn{2}{|c|}{$\begin{array}{c}\text { Very Severe COPD } \\
(n=3)\end{array}$} & \multicolumn{2}{|c|}{ Total } \\
\hline & No & $\%$ & No & $\%$ & No & $\%$ & No & $\%$ & no & $\%$ \\
\hline $41-50$ & 2 & $40 \%$ & 9 & $11.39 \%$ & 2 & $15.38 \%$ & - & & 13 & $13 \%$ \\
\hline $51-60$ & 1 & $20 \%$ & 30 & $37.97 \%$ & 6 & $46.15 \%$ & - & & 37 & $37 \%$ \\
\hline $61-70$ & 1 & $20 \%$ & 21 & $26.58 \%$ & 2 & $15.38 \%$ & 1 & $33.33 \%$ & 25 & $25 \%$ \\
\hline $71-80$ & 1 & $20 \%$ & 19 & $24.05 \%$ & 3 & $23.07 \%$ & 1 & $33.33 \%$ & 24 & $24 \%$ \\
\hline$>80$ & - & - & - & & - & & 1 & $33.33 \%$ & 1 & $1 \%$ \\
\hline Range & \multicolumn{2}{|c|}{$41-77$} & \multicolumn{2}{|c|}{$42-78$} & \multicolumn{2}{|c|}{$40-78$} & \multicolumn{2}{|c|}{$62-82$} & \multicolumn{2}{|c|}{$41-82$} \\
\hline Mean Age & \multicolumn{2}{|c|}{56.40} & \multicolumn{2}{|c|}{61.59} & \multicolumn{2}{|c|}{58.92} & \multicolumn{2}{|c|}{73.67} & \multicolumn{2}{|c|}{61.35} \\
\hline SD & \multicolumn{2}{|c|}{14.31} & \multicolumn{2}{|c|}{9.64} & \multicolumn{2}{|c|}{11.0} & \multicolumn{2}{|c|}{9.07} & \multicolumn{2}{|c|}{10.228} \\
\hline
\end{tabular}

The mild group ranged from 41 yrs. to 77 yrs. with a mean age of $56.40 \pm 14.31$ yrs. The ages in moderate group were 42 yrs. to 78 yrs. and mean 61.59 yrs. and in severe group was 40 yrs. to 78 yrs. and mean $58.92 \pm 11$ yrs. and very severe group were 62 yrs. to 82 yrs. and mean $73.67 \pm$ 9.07 .

Majority of moderate and severe stage COPD patients belonged to 40 to 70 years' age group. Majority of very severe stage COPD patients belonged to 61 - 80 years' age group.

\begin{tabular}{|c|c|c|c|c|c|}
\hline $\begin{array}{c}\text { Sex } \\
\text { Distribution }\end{array}$ & Mild & $\begin{array}{c}\text { Moderate } \\
\text { COPD }\end{array}$ & $\begin{array}{c}\text { Severe } \\
\text { COPD }\end{array}$ & $\begin{array}{c}\text { Very } \\
\text { Severe } \\
\text { COPD }\end{array}$ & Total \\
\hline Males & 4 & 61 & 10 & 2 & $77 \%$ \\
\hline Female & 1 & 18 & 3 & 1 & $23 \%$ \\
\hline \multicolumn{6}{|c|}{ Table 2. Grading of COPD Patients according to Sex } \\
\hline
\end{tabular}

$\mathrm{P}=0.98$ (>0.05 - not significant), chi square -0.208 .

$61 \%$ males and $18 \%$ females belong to moderate COPD, $10 \%$ males and $3 \%$ females belong to severe COPD, $4 \%$ males and $1 \%$ females belong to mild COPD and $2 \%$ males and $1 \%$ females belong to very severe COPD.

\begin{tabular}{|c|c|c|c|c|}
\hline $\begin{array}{c}\text { Smoking } \\
\text { History }\end{array}$ & $\begin{array}{c}\text { Mild } \\
\text { COPD }\end{array}$ & $\begin{array}{c}\text { Moderate } \\
\text { COPD }\end{array}$ & $\begin{array}{c}\text { Severe } \\
\text { COPD }\end{array}$ & $\begin{array}{c}\text { V. Severe } \\
\text { COPD }\end{array}$ \\
\hline Smokers & 5 & 59 & 10 & 2 \\
\hline Non-Smokers & 0 & 20 & 3 & 1 \\
\hline Table 3. Grading of COPD Patients according to Smoking \\
History
\end{tabular}

Most of the patients were active smokers (76\%), most of the females were non-smokers (24\%).

\begin{tabular}{|c|c|c|c|c|c|}
\hline Symptoms & $\begin{array}{c}\text { Mild } \\
\text { COPD }\end{array}$ & $\begin{array}{c}\text { Moderate } \\
\text { COPD }\end{array}$ & $\begin{array}{c}\text { Severe } \\
\text { COPD }\end{array}$ & $\begin{array}{c}\text { Very } \\
\text { Severe } \\
\text { COPD }\end{array}$ & Total \\
\hline Cough & 2 & 48 & 10 & 2 & $62 \%$ \\
\hline $\begin{array}{c}\text { Shortness of } \\
\text { Breath }\end{array}$ & 5 & 74 & 12 & 3 & $94 \%$ \\
\hline Expectoration & 2 & 48 & 10 & 2 & $62 \%$ \\
\hline
\end{tabular}

Table 4. Grading of COPD Patients according to Symptoms

$\mathrm{P}=0.98$ (>0.05 - not significant), chi-square - 0.991 .

Majority of patients in this study having shortness of breath (94\%), 62\% having cough and expectoration.

\begin{tabular}{|c|c|c|c|c|}
\hline COPD & Range & Mean \pm SD & Range & Mean \pm SD \\
\hline Mild & $9.10-15.23$ & $12.42 \pm 2.20$ & $24.10-43.13$ & $34.8 \pm 6.99$ \\
\hline Moderate & $10.50-16.40$ & $12.51 \pm 1.41$ & $30.30-44.73$ & $35.4 \pm 4.39$ \\
\hline Severe & $9.86-16.53$ & $13.39 \pm 2.11$ & $27.40-45.75$ & $37.04 \pm 6.57$ \\
\hline $\begin{array}{c}\text { Very } \\
\text { Severe }\end{array}$ & $9.90-16.73$ & $14.07 \pm 3.66$ & $26.50-46.30$ & $39.05 \pm 11.26$ \\
\hline Total & $9.10-16.73$ & $\mathbf{1 2 . 6 7} \pm 1.65$ & $\mathbf{2 4 . 1 0 - 4 6 . 3 0}$ & $\mathbf{3 5 . 7 5} \pm \mathbf{5 . 0 5}$ \\
\hline Table 5. Grading of COPD patients according to Mean \\
Hb and PCV \\
\hline \multicolumn{5}{|c|}{} \\
\hline
\end{tabular}

$\mathrm{P}<0.05 \mathrm{P}<0.05$ 
Pulmonary Function Tests

\begin{tabular}{|c|c|c|}
\hline Severity of COPD (FEV1\%) & Number of Patients (n = 100) & Percentage \\
\hline Mild $(>80)$ & 5 & $5 \%$ \\
\hline Moderate $(50-80)$ & 79 & $13 \%$ \\
\hline Severe $(30-50)$ & 13 & $3 \%$ \\
\hline Very Severe $(<30)$ & 3 &. \\
\hline
\end{tabular}

$79 \%$ patients belong to moderate COPD, $13 \%$ belong to severe COPD category, $5 \%$ patients belong to mild COPD and 3\% patients belong to very severe COPD.

\begin{tabular}{|c|c|c|c|c|c|}
\hline & Mild & $\begin{array}{c}\text { Moderate COPD } \\
(\mathbf{n = 7 9 )}\end{array}$ & $\begin{array}{c}\text { Severe COPD } \\
(\mathbf{n = 1 3 )}\end{array}$ & $\begin{array}{c}\text { Very Severe COPD } \\
(\mathbf{n = 3})\end{array}$ & $\begin{array}{c}\text { Total } \\
(\mathbf{n = 1 0 0})\end{array}$ \\
\hline $\mathrm{P}$. pulmonale & - & $18(22.78 \%)$ & $3(23.07 \%)$ & $2(66.66 \%)$ & $23(23 \%)$ \\
\hline $\mathrm{R} /$ Sinv $_{1}>1$ & - & $2(2.53 \%)$ & $2(15.38 \%)$ & $1(33.33 \%)$ & $5(5 \%)$ \\
\hline $\mathrm{R} /$ Sinv $_{6}<1$ & - & $11(13.92 \%)$ & $3(23.07 \%)$ & $2(66.66 \%)$ & $16(16 \%)$ \\
\hline Right Axis Deviation & - & $2(2.53 \%)$ & $2(15.38 \%)$ & - & $4(4 \%)$ \\
\hline $\mathrm{RBBB}$ & - & - & $1(7.69 \%)$ & - & $1(1 \%)$ \\
\hline $\mathrm{S}_{1}, \mathrm{~S}_{2}, \mathrm{~S}_{3}$ or $\mathrm{S}_{1} \mathrm{Q}_{3}$ & - & - & - & - \\
\hline
\end{tabular}

\section{Echocardiographic Findings}

Echocardiographic study was carried out in M-mode and 2-D Echocardiography. The following parameters were assessed-

1. RV Area $(\mathrm{cm})^{2}$ : Right ventricular area attend diastole.

2. RA Area $(\mathrm{cm}) 2$ : Right atrial area at end systole.

3. RVAWT (cms): Right ventricular anterior wall (Free wall) thickness.

\begin{tabular}{|c|c|c|c|c|c|c|}
\hline \multirow{2}{*}{ COPD } & \multicolumn{2}{|c|}{ RV Area (cm) } & \multicolumn{2}{c|}{ RA Area (cm) ${ }^{2}$} & \multicolumn{2}{c|}{ RVFWT (cms) } \\
\cline { 2 - 7 } & Range & Mean \pm SD & Range & Mean \pm SD & Range & Mean \pm SD \\
\hline Mild & $9.4-18.2$ & $13.16 \pm 3.29$ & $4.6-9.4$ & $7.3 \pm 1.63$ & $0.3-0.7$ & $0.48 \pm 0.16$ \\
\hline Moderate & $9.4-24.1$ & $14.27 \pm 2.81$ & $5.3-13.4$ & $8.87 \pm 2.32$ & $0.3-1.0$ & $0.60 \pm 0.16$ \\
\hline Severe & $14-26.2$ & $17.30 \pm 3.34$ & $8.2-19.1$ & $10.95 \pm 4.13$ & $0.6-1.1$ & $0.685 \pm 0.12$ \\
\hline Very Severe & $16.1-36.5$ & $25.33 \pm 10.33$ & $12.1-20.4$ & $15.33 \pm 4.14$ & $0.6-1.2$ & $0.867 \pm 0.30$ \\
\hline Total & $\mathbf{9 . 4 - 3 6 . 5}$ & $\mathbf{1 4 . 9 5} \pm \mathbf{3 . 8 3}$ & $\mathbf{4 . 6}-\mathbf{2 0 . 4}$ & $\mathbf{9 . 6 5} \pm \mathbf{2 . 9 3}$ & $\mathbf{0 . 3}-\mathbf{1 . 2}$ & $\mathbf{0 . 7 8} \pm \mathbf{0 . 2 1}$ \\
\hline & $\mathrm{P}<0.05$ & $\mathrm{P}<0.05$ & & $\mathrm{P}<0.05$ \\
\hline
\end{tabular}

In present study, the minimum and maximum values of RV area ranged from $9.4-18.2\left(\mathrm{~cm}^{2}\right)$ with a mean of $13.16 \pm$ $3.29\left(\mathrm{~cm}^{2}\right), 9.4-24.1 \mathrm{~cm}^{2}$ with a mean of $14.27 \pm 2.81\left(\mathrm{~cm}^{2}\right)$ and $14.2-26.2\left(\mathrm{~cm}^{2}\right)$ with a mean of $17.30 \pm 3.34\left(\mathrm{~cm}^{2}\right) 16.1$ $36.5\left(\mathrm{~cm}^{2}\right)$ with a mean of $25.33 \pm 10.33\left(\mathrm{~cm}^{2}\right)$ in Mild, Moderate and Severe and Very Severe COPD respectively.

The minimum and maximum values of RA are arranged from 4.6 - $9.4\left(\mathrm{~cm}^{2}\right)$ with a mean of $7.3 \pm 1.63\left(\mathrm{~cm}^{2}\right), 5.3-13.4$ $\mathrm{cm}^{2}$ with a mean of $8.87 \pm 2.32\left(\mathrm{~cm}^{2}\right)$ and $8.2-19.1\left(\mathrm{~cm}^{2}\right)$ with a mean of $10.95 \pm 4.13\left(\mathrm{~cm}^{2}\right) 16.1-36.5\left(\mathrm{~cm}^{2}\right)$ with a mean of $15.33 \pm 4.14\left(\mathrm{~cm}^{2}\right)$ in Mild, Moderate and Severe and Very Severe COPD respectively.

RVFWT values ranged from $0.3-0.7 \mathrm{~cm}$ with a mean of $0.48 \pm 0.16,0.3-1.0 \mathrm{~cm}$ with a mean of $0.60 \pm 0.16,0.6-1.1$ cms with a mean of $0.685 \pm 0.12$, and $0.6-1.2 \mathrm{cms}$ with a mean of $0.867 \pm 0.30 \mathrm{cms}$ in Mild, Moderate, Severe and Very Severe COPD patients respectively.

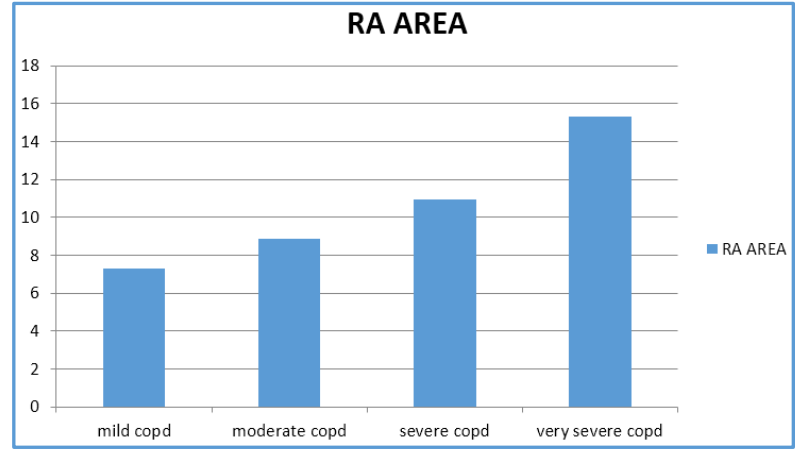

Graph 1. Grading of COPD according to RA Area Comparison

The minimum and maximum values of RA are arranged from $4.6-9.4\left(\mathrm{~cm}^{2}\right)$ with a mean of $7.3 \pm 1.63\left(\mathrm{~cm}^{2}\right), 5.3-13.4$ $\mathrm{cm}^{2}$ with a mean of $8.87 \pm 2.32\left(\mathrm{~cm}^{2}\right)$ and $8.2-19.1\left(\mathrm{~cm}^{2}\right)$ with a mean of $10.95 \pm 4.13\left(\mathrm{~cm}^{2}\right), 16.1-36.5\left(\mathrm{~cm}^{2}\right)$ with a mean of $15.33 \pm 4.14\left(\mathrm{~cm}^{2}\right)$ in Mild, Moderate and Severe and Very Severe COPD respectively. 


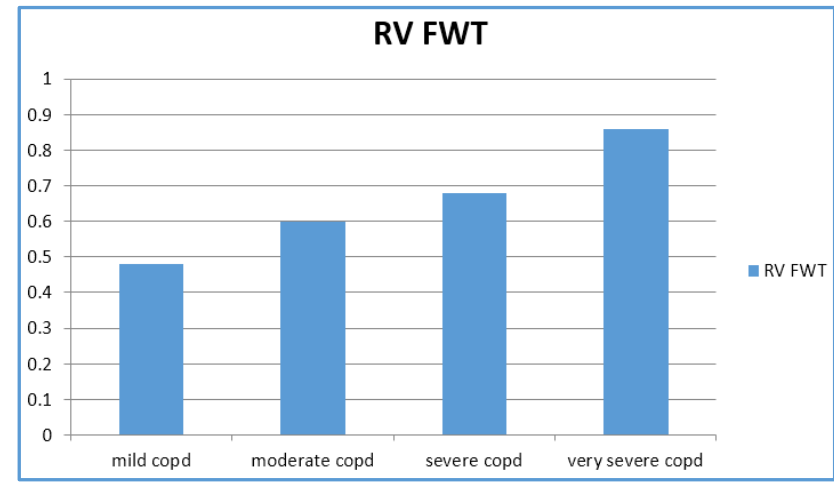

Graph 2. Grading of COPD according to RVFWT Comparison

RVFWT values ranged from $0.3-0.7 \mathrm{~cm}$ with a mean of $0.48 \pm 0.16,0.3-1.0 \mathrm{~cm}$ with a mean of $0.60 \pm 0.16,0.6-1.1$ cms with a mean of $0.685 \pm 0.12$ and $0.6-1.2 \mathrm{cms}$ with a mean of $0.867 \pm 0.30 \mathrm{cms}$ in Mild, Moderate, Severe and Very Severe COPD patients respectively.

\section{Summary}

1. In our present study, 100 patients are studied who attended the outpatient and their mean age is 61.35 .

2. Out of 100 patients, male 77 and females are 23 .

3. COPD patients are divided into 4 groups- Mild, Moderate, Severe and Very Severe groups. FEV1 value is inversely proportionate to severity of COPD.

4. Out of 100,75 patients are smokers and 25 are nonsmokers.

5. The lung function parameters namely $\mathrm{FEV}_{1} \%$ has significant inverse relation between the severity of COPD, progressively decreasing with an increasing severity.

6. On Electrocardiography, the most common abnormality observed was ' $\mathrm{P}$ ' pulmonale, but $\mathrm{R} / \mathrm{S}$ ratio in $\mathrm{V}_{6}<1$ associated significantly with the severity of COPD.

7. Our study emphasises the importance of haematological parameters namely $\mathrm{Hb} \%$ and $\mathrm{PCV}$, were significantly increased in Mild, Moderate and Severe and Very Severe chronic obstructive pulmonary diseases respectively.

\section{DISCUSSION}

The present cross-sectional clinical study was undertaken to investigate the pattern and magnitude of clinical parameters as well as Lab parameters namely ECG, ECHO and Haematological parameters and to investigate the relationship between these verity of the disease and lab parameters.

The study consisted of 100 subjects which were further divided depending upon the severity of the disease, spirometry results, symptoms and previous history of exacerbations into 4 groups that are mild, moderate, severe and very severe according to GOLD guidelines.

Group I has 5 subjects with mild COPD, Group II has 79 subjects with moderate COPD, Group III has 13 subjects with severe COPD and Group 4 has 3 subjects with very severe COPD patients

The aim of the present work was to assess the respective value of physical examination, chest x-ray, ECG, echocardiography and haematological parameters and their relationship between the severity of COPD.

\begin{tabular}{|c|c|}
\hline Study & Mean Age Group \\
\hline Chetan Rati et al ${ }^{4}$ & $53.45 \pm 15.73$ \\
\hline Michel Migueres et al ${ }^{5}$ & $60 \pm 10.81$ \\
\hline Jain et al $^{6}$ & 53 \\
\hline Vikram B Vikhe et al7 & 60.1 \\
\hline Prashantha R Mohapatra et al ${ }^{8}$ & $60 \pm 9$ \\
\hline Present Study & 61.35 \\
\hline \multicolumn{2}{|c|}{$\begin{array}{c}\text { Table 9. Various Studies on Mean Age Group, } \\
\text { comparison of COPD }\end{array}$} \\
\hline
\end{tabular}

In the present study, the age of the patients ranged between $41 \mathrm{yrs}$. and $82 \mathrm{yrs}$. and the mean age was 61.35 .

Present study is similar with other studies like Chetan et al, Jain et al, Vikram B Vikhe et al and Michel Migueres et al in age distributions, i.e. COPD is disease of older age group.

\begin{tabular}{|c|c|c|}
\hline Study & Male & Female \\
\hline Chetan Rati et al ${ }^{4}$ & $74 \%$ & $26 \%$ \\
\hline $\begin{array}{c}\text { Prashantha R Mohapatra } \\
\text { et al }{ }^{8}\end{array}$ & $93.33 \%$ & $6.77 \%$ \\
\hline Michel Migueres et al 5 & $96 \%$ & $4 \%$ \\
\hline Present Study & $77 \%$ & $23 \%$ \\
\hline
\end{tabular}

In present study males account for $77 \%$ with a malefemale ratio of 3.34:1, which is comparable to other studies. Higher prevalence in males may be attributed to smoking. Population based studies of COPD have shown an average prevalence ratio of 6:1. The increase in women COPD patients in our study is probably attributable to increased passive smoking among the rural women of this area and also to exposure to biofuel.

\section{Occupation Distribution}

About $20 \%$ of diagnosed cases of COPD are thought to be attributable to occupation; in lifelong non-smokers, this proportion increases to $30 \%$. Exposure to noxious gases and particles such as grain, isocyanates, cadmium, coal, other mineral dusts and welding fumes- have been implicated in the development of chronic airflow obstruction.

In present study, most of them were farmers (69\%), small proportion were daily wage labourers (31\%), only one belonged to bus driver. Farmers were exposed to various particles like cotton dust, rice grain and wheat grain.

\begin{tabular}{|c|c|c|}
\hline Study & Farmers (\%) & Urban People (\%) \\
\hline Satish Kinagi et al $^{9}$ & 30 & 39 \\
\hline Present Study & 69 & 31 \\
\hline
\end{tabular}

Table 11. Various Studies showing Occupation Comparison

Urban people (daily wage labourer) were exposed to various types of dusts, fumes or environmental pollution

$76 \%$ of patients were smokers. All male patients except 4 had a history of smoking for 5 yrs. or more. In the 20 female and 4 male patients who did not smoke, no definite cause could be established and hence environmental factors, for example air pollution and passive smoking was considered the possible aetiology for COPD in them. The favoured mode of smoking was cigarettes. 


\begin{tabular}{|c|c|c|}
\hline Study & $\begin{array}{c}\text { Smokers } \\
\text { (\%) }\end{array}$ & $\begin{array}{c}\text { Non-Smokers } \\
\text { (\%) }\end{array}$ \\
\hline Chetan Rati et al $^{4}$ & 61 & 39 \\
\hline Lokendra Dave et al $^{10}$ & 87 & 12 \\
\hline $\begin{array}{c}\text { Prashantha R Mohapatra } \\
\text { et al }\end{array}$ & 97 & 3 \\
\hline Present Study & 76 & 24 \\
\hline Table 12. Studies showing History of Smoking \\
Comparison \\
\hline
\end{tabular}

\section{Symptoms Analysis}

In the present study, breathlessness is the most common symptom which is seen in almost $94 \%$ of the patients followed by cough and expectoration in $62 \%$ of the patients indicating these symptoms are present in chronic bronchitis and emphysema subtypes.

\begin{tabular}{|c|c|c|}
\hline Study & Dyspnoea (\%) & Cough (\%) \\
\hline Satish Kinagi et al $^{9}$ & 88.9 & 100 \\
\hline Agarwal et al ${ }^{11}$ & 100 & 100 \\
\hline J. Jain et al ${ }^{12}$ & 66.6 & 85 \\
\hline Vikram B Vikhe et $\mathrm{al}^{7}$ & 88 & 94 \\
\hline Present Study & $94 \%$ & $62 \%$ \\
\hline \multicolumn{3}{|c|}{ Table 13. Comparing Symptoms in Different Studies } \\
\hline
\end{tabular}

Present study differs with other studies in symptoms. In other studies cough is a predominant symptom, whereas in present study dyspnoea is a predominant symptom.

\section{Physical Signs}

Moderately COPD patients in our study did not have raised JVP. Around $11 \%$ of patients with severe obstruction had raised JVP. The signs of right heart failure was significantly more common in patients with severe obstruction. Present study suggests that raised JVP can be considered as a significant sign of severe airway obstruction.

\begin{tabular}{|c|c|c|c|c|}
\hline Study & $\begin{array}{c}\text { JVP } \\
\mathbf{( \% )}\end{array}$ & $\begin{array}{c}\text { Pedal } \\
\text { 0edema } \\
\text { (\%) }\end{array}$ & $\begin{array}{c}\text { Hepatomegaly } \\
\text { (\%) }\end{array}$ & $\begin{array}{c}\text { 0thers } \\
\text { (\%) }\end{array}$ \\
\hline Satish Kinagi et al ${ }^{9}$ & 19.04 & 20.8 & & $\begin{array}{c}\text { Ascites } \\
(22.2)\end{array}$ \\
\hline Agarwal et al ${ }^{11}$ & 22 & 38 & 16 & \\
\hline J. Jain et al ${ }^{8}$ & 33.33 & 50 & 50 & \\
\hline $\begin{array}{c}\text { Vikram B Vikhe et } \\
\text { al }^{7}\end{array}$ & 60 & & \\
\hline Present Study & 11 & 21 & 9 & \\
\hline \multicolumn{5}{|c|}{ Table 14. General Examination comparison } \\
in Different Studies \\
\hline
\end{tabular}

General examination signs like raised JVP and Pedal Oedema, which are signs of cardiac failure seen in proportion with hypoxaemia and hypercapnia, most common in severe and very severe COPD.

In present study, less percentage of raised JVP, Pedal Oedema when compared to other studies because most of COPD patients in present study (79\%) belong to Moderate group (according to GOLD). These findings are seen in severe COPD patients of present study.

\section{Respiratory System Signs}

On examination of the respiratory system diminished respiratory movements, diminished breath sounds, expiratory rhonchi and crepitations were most common signs elicited. These signs along with smoking history guides to diagnose COPD with more accuracy.

\begin{tabular}{|c|c|c|c|}
\hline Study & Wheeze (\%) & Rales (\%) & Both (\%) \\
\hline Agarwal et al $^{11}$ & 61 & 0 & 0 \\
\hline J. Jain et al $^{13}$ & 0 & 93.33 & 0 \\
\hline Present Study & $35 \%$ & $24 \%$ & $4 \%$ \\
\hline Table 15. Comparison of Respiratory System Signs in \\
Different Studies \\
\hline
\end{tabular}

In present study, less percentage of wheeze and rhonchi when compared to other studies because only stable COPD patients were included in the study.

In present study, out of $100(100 \%)$ patients studied 81 (81\%) patients had features suggestive of emphysema on chest x-ray; 29 patients had features of chronic bronchitis. Around 13 (13\%) patients had cardiomegaly and 9 (9\%) patients had prominent pulmonary artery overall. Cardiomegaly was significantly more common in patients with severe COPD group.

\begin{tabular}{|c|c|c|c|c|}
\hline & $\begin{array}{c}\text { Emphysema } \\
\text { (\%) }\end{array}$ & $\begin{array}{c}\text { Ch. } \\
\text { Bronchitis } \\
\text { (\%) }\end{array}$ & $\begin{array}{c}\text { Enlarged } \\
\text { Pulmonary } \\
\text { Artery (\%) }\end{array}$ & $\begin{array}{c}\text { Cardiomegaly } \\
\text { (\%) }\end{array}$ \\
\hline $\begin{array}{c}\text { Agarwal } \\
\text { et al11 }\end{array}$ & 84 & 68 & 0 & 18 \\
\hline $\begin{array}{c}\text { Vikram B } \\
\text { Vikhe } \\
\text { et al } 7\end{array}$ & 38 & 62 & 56 & 48 \\
\hline $\begin{array}{c}\text { Present } \\
\text { Study }\end{array}$ & 81 & 29 & 9 & 13 \\
\hline \multicolumn{5}{|c|}{ Table 16. Radiological Findings comparison in } \\
Different Studies
\end{tabular}

The PFT parameter FEV1\% was significantly altered, FEV1\% was inversely and significantly related to severity of COPD $(\mathrm{P}<0.05)$ decreasing with the severity of COPD.

The $\mathrm{FEV}_{1} \%$ in very severe patients, (mean $23.43 \pm 5.2$ ) was lower than that of mild, moderate, severe patients, (mean $82.46 \pm 1.15 ; 64.1 \pm 6.57 ; 37.78 \pm 5.06)$ respectively. The decrease was statistically significant $(\mathrm{p}<0.05)$.

In present study, the minimum and maximum values of $\mathrm{Hb} \%(\mathrm{~g} / \mathrm{dL})$ ranged from $9.1-15.23$ with a mean of $12.67 \pm$ $1.65,10.50-16.40$ with a mean of $12.51 \pm 1.44,9.86-16.53$ with a mean of $13.39 \pm 2.11$ and $9.90-16.73$ with a mean of $14.07 \pm 3.66$ in mild, moderate, severe, very severe chronic obstructive pulmonary diseases respectively.

The range and mean for patients in all the groups was $9.10 \pm 16.73$ and $12.90 \pm 1.63$ respectively.

The minimum and maximum values of PCV ranged from $4.10-43.13$ with a mean of $34.8 \pm 6.99$ SD, $30.30-44.73$ with a mean of $35.4 \pm 4.39 \mathrm{SD}, 27.40-45.75$ with a mean of 37.04 $\pm 6.57 \mathrm{SD}$ and $26.50-46.30$ with a mean of $39.05 \pm 11.26 \mathrm{SD}$ in mild, moderate, severe and very severe COPD patients respectively. The range and mean for patients in all the groups were $24.10 \pm 46.30$ and $35.80 \pm 5.05$ respectively.

Both $\mathrm{Hb} \%$ and PCV are significantly higher in patients with severe obstruction compared to the other two groups $(\mathrm{p}<0.05)$.

In a study by Vlahakos et al, the mean $\mathrm{Hb} \%$ and PCV were $17.2 \pm 0.05 \mathrm{~g} / \mathrm{dL}$ and $56 \pm 0.09$ respectively. The difference between $\mathrm{Hb} \%$ and PCV between the present study and study by Vlahakos et al, may be due to the fact that the number of 
patients included in the latter study was small (13). Patients with severe COPD and the baseline $\mathrm{Hb} \%$ and PCV in normal population is more in Western population compared to the Indian population.

\begin{tabular}{|c|c|c|}
\hline Study & Hb\% & PCV \\
\hline Vlahakos et al $^{12}$ & 17.2 & 56 \\
\hline Present Study & 12.90 & 36.80 \\
\hline
\end{tabular}

In present study, out of total 100 patients, 49 (49\%) patients showed ECG changes suggestive of involvement of right side of the heart. The most common abnormality observed was ' $\mathrm{P}$ ' pulmonale (Moderate- 17.72\%, Severe$23.07 \%$ and Very Severe- $66.66 \%$ ). 'P' pulmonale was seen more commonly in patients with severe obstruction, although not statistically significant. The $\mathrm{R} / \mathrm{S}$ ratio in $\mathrm{V}_{6}<1$ correlated significantly well with the severity of COPD, 11 (13.922\%) in moderate COPD, 3 (23.07\%) in severe COPD and 2 (66.66\%) patients in very severe COPD group had this abnormality.

\begin{tabular}{|c|c|}
\hline Vineet Alexander et $\mathrm{al}^{3}$ & $52.6 \%$ \\
\hline Radha Krishnan et al ${ }^{14}$ & $25 \%$ \\
\hline Satish Kinagi et al ${ }^{9}$ & $33.33 \%$ \\
\hline Agarwal et al ${ }^{11}$ & $44 \%$ \\
\hline Hina Banker et al ${ }^{15}$ & $35 \%$ \\
\hline Present Study & $23 \%$ \\
\hline
\end{tabular}

\begin{tabular}{|c|c|}
\hline${\text { Radha Krishnan et } \text { al }^{14}}$ & $17 \%$ \\
\hline Agarwal et al $^{11}$ & $30 \%$ \\
\hline Lokendra Deva et al $^{10}$ & $36.5 \%$ \\
\hline Hina Banker et al & $62 \%$ \\
\hline Present Study & $16 \%$ \\
\hline
\end{tabular}

Table 35 RVH Comparison

Table 19. $R / S$ Ratio in $V_{6}<1$ in Various Studies

\begin{tabular}{|c|c|}
\hline${\text { Radha Krishna et } \mathrm{al}^{5}}$ & $16 \%$ \\
\hline Satish Kinagi et al $^{7}$ & $56.9 \%$ \\
\hline Agarwal et al $^{10}$ & $26 \%$ \\
\hline Lokendra Deva et al $^{11}$ & $40 \%$ \\
\hline Hina Banker et al & $65 \%$ \\
\hline Present Study & $4 \%$ \\
\hline Table 20. Right Axis Deviation in Various Studies
\end{tabular}

Table 20. Right Axis Deviation in Various Studies

The reason for the differences in the ECG findings in present study may be due to the fact that the sample size was small and also as we had categorised the patients to different groups compared to the other studies, which were carried out on large number of patients without categorisation, most of our patients belong to moderate COPD. Other manifestations like RBBB (Prolonged QRS $>0.10$ sec broad terminal $S$ wave in lead 1, V5, V6 and RSR complex in V1) are also seen in about 8 cases $(8 \%)$.

The rates at which dependable images could be obtained by echocardiographic examination in patients with COPD have shown a wide variation in studies by different authors and in different views viz. Lesser et al (1983), Oswald Mammoser et al (1987) and Himelman et al (1988). The percentage of successful echo studies ranged from $91 \%$ (Himelman et al) using the apical view to only $42 \%$ by some authors using the parasternal view. Intermediate values were obtained by Oswald Mammoser et al (83\% using the Mmode) and Bertoli et al (approx. 86\%) and Tsuda et al (80\%).

Mean values of different parameters of Echocardiography in normal subjects as observed by different authors. The following table shows the comparison of the values obtained in different studies for some of the parameters studied.

\begin{tabular}{|c|c|c|c|c|c|c|}
\hline \multirow[t]{2}{*}{ Authors } & \multicolumn{2}{|c|}{ RVAWT (cms) } & \multicolumn{2}{|c|}{ RV Area $\left(\mathrm{cm}^{2}\right)$} & \multicolumn{2}{|c|}{ RA Area $\left(\mathrm{cm}^{2}\right)$} \\
\hline & & & & Mean --- & Range --- & Mean --- \\
\hline Louridas et al (1980)16 & --- & $0.88 \pm 0.19$ & --- & & & \\
\hline Bertoli et al ${ }^{17}$ & --- & 0.4 & --- & --- & --- & --- \\
\hline Tsudaetal $^{18}$ & $0.18-0.35$ & 0.24 & $-\cdots$ & --- & --- & --- \\
\hline Mutsukobo ${ }^{19}$ et al & --- & 0.34 & --- & --- & --- & --- \\
\hline Cacho et al & --- & --- & --- & $6.9 \pm 0.74$ & --- & $4 \pm 0.33$ \\
\hline$(1983)^{20}$ Zenker et al (1985) ${ }^{21}$ & --- & $0.54 \pm 0.08$ & --- & $12.2 \pm 2.23$ & --- & --- \\
\hline Foele et al & --- & 0.4 & --- & -- & --- & --- \\
\hline Danchin et al (1987) ${ }^{22}$ & --- & --- & --- & $15.3 \pm 4.2$ & --- & --- \\
\hline
\end{tabular}

\begin{tabular}{|c|c|c|c|c|c|c|}
\hline \multirow[t]{2}{*}{ Authors } & \multicolumn{2}{|c|}{ RVAWT (cms) } & \multicolumn{2}{|c|}{ RV Area $\left(\mathrm{cm}^{2}\right)$} & \multicolumn{2}{|c|}{ RA Area $\left(\mathrm{cm}^{2}\right)$} \\
\hline & Range & Mean & Range & Mean & Range & Mean \\
\hline 1. $\quad$ Mutsukobo et al ${ }^{19}$ & $0.4-0.9$ & $0.6 \pm 0.13$ & +-- & --- & --- & --- \\
\hline 2. $\quad$ Tsuda et al ${ }^{18}$ & $0.25-1.6$ & $0.46 \pm 0.31$ & --- & --- & $-\cdots$ & --- \\
\hline 3. Cacho et $\mathrm{a}^{120}$ & --- & --- & $-\cdots$ & $13.02 \pm 3.64$ & --- & 8. 2.79 \\
\hline 4. $\quad$ Zenker et $\mathrm{al}^{21}$ & $-\cdots$ & $1.22 \pm 0.223$ & --- & --- & --- & --- \\
\hline 5. $\quad$ Bertoli et al ${ }^{17}$ & $-\cdots$ & $0.54 \pm 0.14$ & $-\cdots$ & --- & --- & --- \\
\hline $\begin{array}{ll}6 . & \text { Oswald } 23 \\
\end{array}$ & $-\cdots$ & $0.61 \pm 0.12$ & --- & & --- & \\
\hline \multicolumn{7}{|l|}{ Mammoser et al } \\
\hline Present Study & & $0.48 \pm 0.16$ & & & & \\
\hline -Mild COPD & $0.3-0.7$ & & $9.2-18.2$ & $13.16 \pm 3.29$ & $5.3-9.4$ & $7.3 \pm 1.63$ \\
\hline Moderate COPD & $0.3-1$ & $0.606 \pm 0.16$ & $9.4-24.1$ & $14.27 \pm 2.81$ & $5.3-13.4$ & $8.87 \pm 2.32$ \\
\hline Severe COPD & $0.6-1$ & $0.685 \pm 0.12$ & $14-26.2$ & $17.3 \pm 3.34$ & $7-19.1$ & $10.95 \pm 4.13$ \\
\hline Very Severe COPD & $0.6-1.2$ & $0.867 \pm 0.30$ & $16.1-36.5$ & $25.33 \pm 10.33$ & $12.1-20.4$ & $15.33 \pm 4.44$ \\
\hline
\end{tabular}




\section{CONCLUSION}

1. The lung function parameters namely $\mathrm{FEV}_{1} \%$ has significant inverse relation between the severity of COPD, progressively decreasing with the increasing severity.

2. On Electrocardiography, the most common abnormality observed was ' $\mathrm{P}$ ' pulmonale, but $\mathrm{R} / \mathrm{S}$ ratio in $\mathrm{V}_{6}<1$ significantly associated with the severity of COPD.

3. In the Echocardiographic study, the right heart parameters were significantly increased in Mild, Moderate and Severe and Very Severe COPD respectively.

4. Our study emphasises the importance of haematological parameters, namely $\mathrm{Hb} \%$ and PCV were significantly increased in Mild, Moderate and Severe and Very Severe chronic obstructive pulmonary diseases respectively.

\section{REFERENCES}

[1] World Health Report. Geneva: World Health Organization. Available from URL:

http://www.who.int/whr/2000/en/statistics.htm; 2000.

[2] Lopez AD, Shibuya K, Rao C, et al. Chronic obstructive pulmonary disease: current burden and future projections. Eur Respir J 2006;27(2):397-412.

[3] Alexander V, Pajanivel R, Menon KS, et al. Prevalence of cardiac comorbidities and its relation to severity staging of chronic obstructive pulmonary disease. IJCRR 2015;7(17):27-33.

[4] Rathi C, Wanjari A, Acharya S. Pulmonary hypertension in mild- moderate COPD: an early link. Journal of Evidence based Medicine and Healthcare 2015;2(42):7330-40.

[5] Miguéres M, Escamilla R, Coca F, et al. Pulsed Doppler echocardiography in diagnosis of pulmonary hypertension in COPD. CHEST 1990;98(2):280-5.

[6] Jain BK, Pasari N, Bajpai A, et al. Evaluation of right ventricular dysfunction and pulmonary artery hypertension secondary to COPD severity by electrocardiogram and echocardiography. Journal of Evolution of Medical and Dental Sciences 2015;4(42):7275-81.

[7] Vikhe VB, Shende PS, Patil RS, et al. Cardiovascular complications in chronic obstructive pulmonary disease with reference to 2D echocardiography findings. National journal of medical research 2013;3(4):385-8.

[8] Mohapatra PR, Janmeja AK. Factors associated with hospital admission in patients with acute exacerbation of COPD. CHEST 2011;52:203-6.

[9] Kinagi S, Patil S, Afiya S. Analysis of chronic obstructive pulmonary disease with clinical parameters, ECG and ECHO. Journal of Evolution of Medical and Dental Sciences 2014;3(57):12864-80.

[10] Dave L, Dwivedi P, Srivastava N, et al. A study of cardiovascular manifestations of COPD. Int J Res Health Sci 2014;2(3):812-7.
[11] Agarwal KC, Sing D, Shital P, et al. Cardiovascular alterations in COPD what hurts the patient the most. Journal of Medical Education \& Research 2013;3(1):21-30.

[12] Vlahakos DV, Kosmas EN, Dimopoulou I, et al. Losartan reduces hematocrit in patients with chronic obstructive pulmonary disease and secondary erythrocytosis. Ann Intern Med 2001;134(5):426-7.

[13] Jain J, Soni P, Apte S, et al. A study of correlation between the echocardiography changes with the duration and severity of chronic obstructive pulmonary disease. Journal of Evolution of Medical and Dental Sciences 2014;3(8):1997-2002.

[14] Krishnan DR, Srihari B. A study on the severity of right ventricular dysfunction in correlation with the severity of lung dysfunction in chronic obstructive pulmonary disease patients - COPD. The Ame J Sci \& Med Res 2015;1(1):112-9.

[15] Banker H, Verma A. Electrocardiographic changes in COPD. NHL Journal of Medical Sciences 2013;2(2):558.

[16] Louridas G, Angomachalelis N, Patakas D, et al. Right ventricular echocardiographic vectorcardiographic and electrocardiographic study in cor pulmonale. Acta cardiol 1980;35(6):429-36.

[17] Bertoli L, Mantero A, Alpago R, et al. Value of two dimensional echocardiography in the identification of pulmonary hypertension in chronic obstructive lung disease. Respiration 1989;55(4):193-201.

[18] Tsuda T, Sawayama T, Kawai N, et al. Echocardiographic measurements of right ventricular wall thickness in adults by anterior approach. Br Heart J 1980;44(1):55-61.

[19] Matsukubo H, Matsuura T, Endo N, et al. Echocardiographic measurements of right ventricular wall thickness. A new application of subxiphoid echocardiography. Circulation 1977;56:278-84.

[20] Cacho A. Usefulness of two dimensional echocardiography in diagnosing right ventricular hypertrophy. Chest 1988;84:154.

[21] Zenker G, Forche G, Harwoncourt K. Two-dimensional echocardiography using a subcostal approach in patients with COPD. Chest 1985;88(5):722-5.

[22] Danchin N, Cornette A, Henriquez A, et al. Twodimensional echocardiographic assessment of right ventricle in patients with chronic obstructive lung disease.; Chest 1987;92(2):229-33.

[23] Oswald-Mammosser M, Oswald T, Nyankiye E, et al. Non- invasive diagnosis of pulmonary hypertension in chronic obstructive pulmonary disease. Comparison of ECG, radiological measurements, echocardiography and myocardial scintigraphy. Eur J Respir Dis 1987;71(5):419-29. 